\title{
Uncalibrated pulse power analysis fails to reliably measure cardiac output in patients undergoing coronary artery bypass surgery
}

\author{
Ole Broch ${ }^{1 *}$, Jochen Renner ${ }^{1}$, Jan Höcker ${ }^{1}$, Matthias Gruenewald ${ }^{1}$, Patrick Meybohm¹, Jan Schöttler², \\ Markus Steinfath ${ }^{1}$, Berthold Bein ${ }^{1}$
}

\begin{abstract}
Introduction: Uncalibrated arterial pulse power analysis has been recently introduced for continuous monitoring of cardiac index $(\mathrm{Cl})$. The aim of the present study was to compare the accuracy of arterial pulse power analysis with intermittent transpulmonary thermodilution (TPTD) before and after cardiopulmonary bypass (CPB).

Methods: Forty-two patients scheduled for elective coronary surgery were studied after induction of anaesthesia, before and after CPB respectively. Each patient was monitored with the pulse contour cardiac output (PiCCO) system, a central venous line and the recently introduced LiDCO monitoring system. Haemodynamic variables included measurement of $\mathrm{Cl}$ derived by transpulmonary thermodilution ( $\mathrm{Cl}_{\text {TPTD }}$ ) or $\mathrm{Cl}$ derived by pulse power analysis $\left(\mathrm{Cl}_{\text {PP }}\right)$, before and after calibration ( $\mathrm{Cl}_{\text {PPnon-cal., }} \mathrm{Cl}_{\text {PPcal. }}$.) Percentage changes of $\mathrm{Cl}\left(\Delta \mathrm{Cl}_{T P T D}, \Delta \mathrm{Cl}_{\text {PPnon-cal./PPcal. }}\right)$ were calculated to analyse directional changes.

Results: Before CPB there was no significant correlation between $C_{\text {PPnon-cal. }}$ and $\mathrm{Cl}_{\text {TPTD }}\left(\mathrm{r}^{2}=0.04, P=0.08\right)$ with a percentage error (PE) of $86 \%$. Higher mean arterial pressure (MAP) values were significantly correlated with higher $C_{\text {ppnon-cal. }}\left(r^{2}=0.26, P<0.0001\right)$. After $C P B, C l_{\text {ppcal. }}$ revealed a significant correlation compared with $\mathrm{Cl}_{\text {TPTD }}\left(\mathrm{r}^{2}=\right.$ $0.77, P<0.0001)$ with $P E$ of $28 \%$. Changes in $C_{\text {PPcal. }}\left(\Delta C_{\text {PPcal }}\right.$.) showed a correlation with changes in $C_{\text {TPTD }}\left(\left.\Delta C\right|_{\text {TPTD }}\right)$ only after CPB $\left(r^{2}=0.52, P=0.005\right)$.

Conclusions: Uncalibrated pulse power analysis was significantly influenced by MAP and was not able to reliably measure Cl compared with TPTD. Calibration improved accuracy, but pulse power analysis was still not consistently interchangeable with TPTD. Only calibrated pulse power analysis was able to reliably track haemodynamic changes and trends.
\end{abstract}

\section{Introduction}

Measuring left ventricular stroke volume and cardiac index $(\mathrm{CI})$ have gained increasing impact regarding perioperative monitoring of critically ill patients either in the operating theatre or on the intensive care unit. Goal-directed perioperative optimization of left ventricular stroke volume and CI have a positive impact on the morbidity and the length of stay on the intensive care unit [1-4]. Measurement of CI with the pulmonary artery catheter (PAC) is still widely used and often

\footnotetext{
* Correspondence: broch@anaesthesie.uni-kiel.de

'Department of Anaesthesiology and Intensive Care Medicine, University Hospital Schleswig-Holstein, Campus Kiel, Schwanenweg 21, 24105 Kiel, Germany

Full list of author information is available at the end of the article
}

considered as a kind of "gold standard" in different clinical settings $[5,6]$. However, several studies showed that pulmonary artery catheterization has clinical limitations and bares the potential risk for severe complications [7-9]. In this context, interest has focused on less invasive techniques which are based for example on transpulmonary thermodilution (TPTD) or arterial waveform analysis $[6,10,11]$. Alternative methods of haemodynamic monitoring for estimating $\mathrm{CI}$ such as transpulmonary thermodilution differ from pulmonary artery thermodilution and are theoretically more sensitive to thermal blood loss and changes such as recirculation and forward-backward movement, especially in the presence of left-sided valvular insufficiencies [12]. It has been 
repeatedly shown, however, that pulmonary artery thermodilution and transpulmonary thermodilution are interchangeable in different patient populations and during different surgical procedures [6,13-15].

The recently introduced LiDCO monitoring system (LiDCO Rapid; LiDCO Group Ltd, London, UK) consists of an arterial pressure waveform analysis that provides beat-to-beat measurement of $\mathrm{CI}$ by analysis of the arterial blood pressure tracing. The underlying pulse power algorithm (PulseCO) originally was introduced as an algorithm requiring calibration by lithium indicator dilution to determine the individual vascular compliance and has been evaluated in different clinical scenarios $[16,17]$. Using a nomogram to assess the patient specific aortic compliance, the new software version estimates stroke volume without the need for calibration. Furthermore, this device offers the possibility of calibration by a reference technique. Based on these updates, $\mathrm{LiDCO}_{R a-}$ pid only requires a standard radial arterial line and is claimed to mirror CI or trends of CI reliably. However, calculation of cardiac index by arterial pressure waveform analysis could be influenced by several confounders, like changes in vascular tone or vasoactive drugs $[18,19]$. Specifically, it has been shown that methods based on arterial waveform analysis are prone to failure after cardiopulmonary bypass (CPB), when major changes in vascular resistance are likely to occur [15].

Therefore, the aim of the present study was to investigate the accuracy of uncalibrated and calibrated pulse power analysis $\left(\mathrm{CI}_{\mathrm{PPnon} \text {-cal. }}, \mathrm{CI}_{\mathrm{P} \text { Pcal. }}\right)$ with respect to simultaneous measurements and the ability to track haemodynamic changes $\left(\Delta \mathrm{CI}_{\mathrm{TPTD}}, \Delta \mathrm{CI}_{\mathrm{PPnon} \text {-cal./cal. }}\right)$, both before and after $\mathrm{CPB}$.

\section{Materials and methods}

Approval from our institutional ethics committee (Christian Albrecht University Kiel) was obtained and all patients gave informed consent for participation in the study.

Forty-two patients undergoing elective coronary artery bypass grafting (CABG) were studied after induction of general anaesthesia. Inclusion criteria were as follows: patients $>18$ years of age with a left ventricular ejection fraction $\geq 0.5$. Patients with emergency procedures, haemodynamic instability requiring inotropic and/or vasoactive pharmacologic support, intracardiac shunts, severe aortic-, tricuspid- or mitral stenosis or insufficiency, and patients on an intra-aortic balloon pump were all excluded from the study.

\section{Instrumentation and protocol}

All patients were pre-medicated with midazolam 0.1 $\mathrm{mg} \cdot \mathrm{kg}^{-1}$ orally 30 minutes before induction of anaesthesia. Routine monitoring was established including non- invasive blood pressure (NIBP), peripheral oxygen saturation $\left(\mathrm{SpO}_{2}\right)$ and heart rate (HR) by electrocardiogram (ECG; S/5, GE Healthcare, Helsinki, Finland). Subsequently patients received a peripheral venous access and a radial arterial pressure catheter. The $\mathrm{LiDCO}_{\text {Rapid }}$ monitor was connected to the S/5 monitor and started after input of patient specific data according to the manufacturer's instructions. After induction of anaesthesia with sufentanil $\left(0.5 \mu \mathrm{g} \cdot \mathrm{kg}^{-1}\right)$ and propofol $\left(1.5 \mathrm{mg} \cdot \mathrm{kg}^{-1}\right)$, orotracheal intubation was facilitated with rocuronium $\left(0.6 \mathrm{mg} \cdot \mathrm{kg}^{-1}\right)$. Anaesthesia was maintained with sufentanil $\left(1 \mu \mathrm{g} \cdot \mathrm{kg}^{-1} \cdot \mathrm{h}^{-1}\right)$ and propofol $\left(3 \mathrm{mg} \cdot \mathrm{kg}^{-1} \cdot \mathrm{h}^{-1}\right)$. Patients were ventilated with an oxygen/air mixture using a tidal volume of $8 \mathrm{ml} \cdot \mathrm{kg}^{-1}$ and positive end-expiratory pressure was set at $5 \mathrm{cmH}_{2} \mathrm{O}$. A central venous catheter and a thermodilution catheter (Pulsion Medical Systems, Munich, Germany) were introduced in the right internal jugular vein, respectively in the femoral artery and the thermodilution catheter was connected to the PiCCO monitor (PiCCOplus, software version 6.0; Pulsion Medical Systems, Munich, Germany).

\section{Data collection}

Measurements of $\mathrm{CI}_{\mathrm{TPTD}}$ were performed every $15 \mathrm{~min}$ utes by injecting $15 \mathrm{ml}$ ice cold saline $\left(\leq 8^{\circ} \mathrm{C}\right)$ through the central venous line. Injections were repeated at least three times and randomly assigned to the respiratory cycle. In case of a difference with respect to the preceding $\mathrm{CI}_{\mathrm{TPTD}}$ measurement of $\geq 15 \%$, the value obtained was discarded and the measurement repeated. Measurements of $\mathrm{CI}_{\mathrm{PP}}$ were performed by plotting 10 numerical values over a period of one minute, excluding variations $\geq 15 \%$ and determining the mean value. Mean arterial pressure and CVP were also recorded every 15 minutes. Values of $\mathrm{CI}_{\mathrm{PPnon} \text {-cal., }}$ and $\mathrm{CI}_{\mathrm{PP} \text { cal. }}$ were collected during a one minute period and averaged. After induction of anaesthesia, haemodynamic variables including $\mathrm{CI}_{\mathrm{TPTD}}$ and $\mathrm{CI}_{\mathrm{PPnon} \text {-cal. }}$ were recorded every 15 minutes up to 30 minutes (T1), which means two pairs of measurements. After 30 minutes, calibration of pulse power analysis $\left(\mathrm{CI}_{\mathrm{PPcal}}\right)$ was performed and measurements were recorded until the beginning of $\mathrm{CPB}$ (T2), which differed from patient to patient yielding different numbers of measurements in this time period. Measurements were restarted 15 minutes after weaning from CPB. Subsequently, measurements of $\mathrm{CI}_{\mathrm{TPTD}}$ and $\mathrm{Cl}_{\mathrm{PPnon} \text {-cal. were }}$ obtained up to 45 minutes (T3), yielding three pairs of measurements. After 45 minutes, re-calibration of pulse power analysis $\left(\mathrm{CI}_{\mathrm{PPcal}}\right)$ was carried out and haemodynamic variables were recorded until the patient was discharged to the intensive care unit (T4), again yielding a different number of measurement pairs in individual patients. Two patients were discharged to the intensive care unit 45 minutes after $\mathrm{CPB}$, therefore, $\mathrm{CI}_{\mathrm{PP} \text { cal. }}$. 
measurements were not available from these patients. The study design is displayed in Figure 1.

\section{Statistical analysis}

All data are given as mean \pm SD. Statistical comparisons were performed using commercially available statistics software (GraphPad Prism 5, GraphPad Software Inc., San Diego, CA, USA, Software R, R Foundation for Statistical Computing, Vienna, Austria and PASS Version 11, NCSS, LLC. Kaysville, UT, USA). To demonstrate the relationship between sample size and the width of the confidence interval of the estimated variable, we calculated the width of the $95 \%$ confidence interval of the limits of agreement ( 0.52 standard deviations of the bias). To describe the agreement between $\mathrm{CI}_{\mathrm{TPTD}}, \mathrm{CI}_{\mathrm{PP}-}$ non-cal. and $\mathrm{CI}_{\mathrm{PPcal}}$, Bland-Altman plots were calculated for each time period (T1 to T4) before and after CPB. Percentage error was calculated as described by Critchley and colleagues, using the limits of agreement (2SD) of the bias divided by the mean $\mathrm{CI}$ values from $\mathrm{CI}_{\mathrm{TPTD}}$, $\mathrm{CI}_{\mathrm{PPnon}-\text { cal. }}$ and $\mathrm{CI}_{\mathrm{PP} \text { cal. }}$. Bland-Altman plots were also performed for haemodynamic trends $\left(\Delta \mathrm{CI}_{\mathrm{TPTD}}, \Delta \mathrm{CI} \mathrm{IP}_{\mathrm{PP}}\right.$ non-cal. and $\Delta \mathrm{CI}_{\mathrm{PP} \text { cal. }}$.) before and after CPB. $\Delta \mathrm{CI}_{\mathrm{TPTD}}$ $<15 \%$ were excluded from analysis as recommended by Critchley and co-workers [20]. To describe the discriminative power of $\Delta \mathrm{CI}_{\mathrm{PPnon} \text {-cal. }}$ and $\Delta \mathrm{CI}_{\mathrm{PP} \text { cal. }}$ predicting true changes in $\mathrm{CI}_{\mathrm{TPTD}}(>15 \%)$ ROC analysis was performed. Post hoc power of ROC analysis was calculated with PASS software. Dependent upon the number of subjects enrolled at each time point (T1 to T4) the difference with respect to AUC between the null hypothesis $(\mathrm{AUC}=0.50)$ and the alternative hypothesis (AUC of $\Delta \mathrm{CI}_{\mathrm{PPnon} \text {-cal. }}$ and $\left.\Delta \mathrm{CI}_{\mathrm{PP} \text { cal. }}>0.50\right)$ that could be detected ranged from 0.28 to 0.32 for an $\alpha=0.05$ and a $\beta=0.20$. An unpaired sample t-test was used to analyse significant differences of mean arterial pressure related to the periods of measurement.

\section{Results}

Data from all 42 patients, 31 males and 11 females, were included in the final analysis. Ages ranged between 41 to 78 years, with a mean age of $63 \pm 5$ and a mean body mass index of $27.4 \pm 4.9 \mathrm{~kg} / \mathrm{m}^{2}$. Mean left ventricular ejection fraction was $0.58 \pm 0.04 \%$. A total of 430 data pairs (T1: 84, T2: 164, T3: 123, T4: 59) were obtained during the study period. An unpaired t-test showed a significant difference $(P<0.05)$ between MAP values before (T1, T2) and after cardiopulmonary bypass (T3, T4). Haemodynamic and respiratory variables are shown in Table 1.

There was no significant correlation between $\mathrm{CI}_{\mathrm{PPnon}-}$ cal. and $\mathrm{CI}_{\mathrm{TPTD}}\left(\mathrm{r}^{2}=0.04, P=0.08, \mathrm{n}=84\right)$ within the first 30 minutes (T1) after induction of anaesthesia (Figure 2). Bland-Altman analysis showed a mean bias of $0.36 \mathrm{~L} / \mathrm{minute} / \mathrm{m}^{2}$ (95\% limits of agreement (LOA): -1.73 to $+2.46 \mathrm{~L} /$ minute $/ \mathrm{m}^{2}$ ) with a percentage error (PE) of $86 \%$. Bias, LOA and PE for each time period (T1 to T4) are summarized in Table 2. Correlation between

\section{Time points}

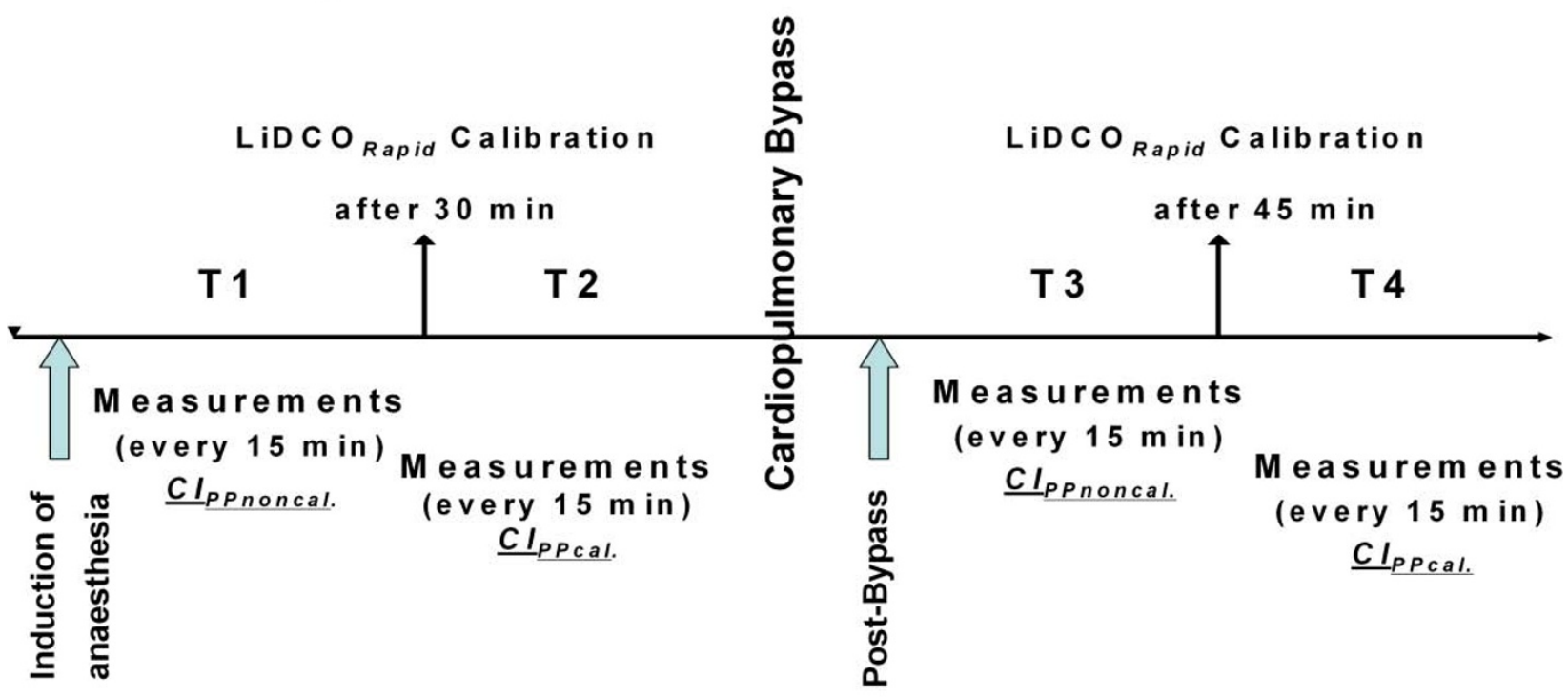

Events

Figure 1 Study design. T1: data collection after induction of anaesthesia until calibration (Clppnon-cal). T2: after calibration until cardiopulmonary bypass (Clppcal.). T3: after cardiopulmonary bypass until calibration (Clppnon-cal). T4: after calibration until discharge to the intensive care unit $(\mathrm{Cl}$ ppcal. $)$. 
Table 1 Haemodynamic and respiratory variables at different time points

\begin{tabular}{|c|c|c|c|c|c|c|c|}
\hline \multirow[b]{2}{*}{ Variables } & \multirow[b]{2}{*}{ Time points Data pairs } & \multicolumn{3}{|c|}{ Pre - Bypass } & \multicolumn{3}{|c|}{ Post - Bypass } \\
\hline & & $T 1 n=84$ & $\mathrm{~T} 2 \mathrm{n}=164$ & $P$ & $T 3 n=123$ & $\mathrm{~T} 4 \mathrm{n}=59$ & $P$ \\
\hline HR (minute ${ }^{-1}$ ) & & $55 \pm 2$ & $56 \pm 3$ & $P P=0.45$ & $80 \pm 3^{\S}$ & $82 \pm 2^{\S}$ & $P P=0.33$ \\
\hline MAP $(\mathrm{mmHg})$ & & $83 \pm 17$ & $76 \pm 12$ & $P<0.05$ & $68 \pm 7^{\S}$ & $67 \pm 5^{\S}$ & $P=0.98$ \\
\hline CVP $(\mathrm{mmHg})$ & & $10 \pm 2$ & $11 \pm 2$ & $P=0.54$ & $9 \pm 1$ & $11 \pm 1$ & $P 0=0.10$ \\
\hline Lung compliance $\left(\mathrm{mL} / \mathrm{cmH}_{2} \mathrm{O}\right)$ & & $51 \pm 2$ & $53 \pm 1$ & $P=0.22$ & $50 \pm 2$ & $49 \pm 2$ & $P=0.67$ \\
\hline Tidal volume $(\mathrm{mL})$ & & $675 \pm 75$ & $686 \pm 69$ & $P=0.15$ & $700 \pm 72$ & $695 \pm 70$ & $P=0.39$ \\
\hline SVRI (dynes $s / \mathrm{cm}^{5} / \mathrm{m}^{2}$ ) & & $2,712 \pm 68$ & $2,096 \pm 327$ & $P<0.05$ & $1,659 \pm 141^{\S}$ & $1729 \pm 138^{\S}$ & $P=0.11$ \\
\hline $\mathrm{Cl}_{\text {PPnon-cal. }}\left(\mathrm{L} /\right.$ minute $\left./ \mathrm{m}^{2}\right)$ & & $2.5 \pm 0.7$ & & & $3.4 \pm 0.2 *$ & & \\
\hline $\mathrm{Cl}_{\text {PPcal. }}\left(\mathrm{L} /\right.$ minute $\left./ \mathrm{m}^{2}\right)$ & & & $2.6 \pm 0.2$ & & & $3.2 \pm 0.1^{\#}$ & \\
\hline $\mathrm{Cl}_{\text {TPTD }}\left(\mathrm{L} /\right.$ minute $\left./ \mathrm{m}^{2}\right)$ & & $2.3 \pm 0.1$ & $2.4 \pm 0.1$ & $P=0.17$ & $3.3 \pm 0.2^{\S}$ & $3.3 \pm 0.2^{\S}$ & $P=0.55$ \\
\hline
\end{tabular}

$\mathrm{HR}$, heart rate; MAP, mean arterial HR, heart.

$\mathrm{Cl}_{\text {PPnon-cal, }}$ cardiac index by uncalibrated pulse power analysis; $\mathrm{Cl}_{\text {PPcal., }}$ cardiac index by calibrated pulse power analysis; $\mathrm{Cl}_{\mathrm{TPTD}}$, cardiac index by transpulmonary thermodilution; CVP, central venous pressure; HR, heart rate; MAP, mean arterial pressure, stroke volume index by transpulmonary thermodilution; SVRI, systemic vascular resistance index; $S V_{\text {TPTD }}$. Values are given as mean $\pm S D$.

${ }^{\S} P<0.05$ (vs. T1, T2), * $P<0.05$ (vs. T1), ${ }^{\#} P<0.05$ (vs. T2).

$\mathrm{CI}_{\mathrm{TPTD}}$ and $\mathrm{CI}_{\mathrm{PP}}$ is shown in Figure 2. $\mathrm{CI}_{\mathrm{PP} \text { cal. }}$ (T2) revealed a significant correlation with $\mathrm{CI}_{\mathrm{TPTD}}\left(\mathrm{r}^{2}=0.42\right.$, $P<0.0001, \mathrm{n}=164$ ) and Bland-Altman analysis showed a mean bias of $0.075 \mathrm{~L} /$ minute $^{1} / \mathrm{m}^{2}$ (LOA: -1.19 to + $1.34 \mathrm{~L} / \mathrm{minute} / \mathrm{m}^{2}$ ) with a PE of $55 \%$. A significant correlation $\left(\mathrm{r}^{2}=0.30, P<0.0001, \mathrm{n}=123\right)$ between $\mathrm{CI}_{\text {PPnon-cal. }}$ and $\mathrm{CI}_{\mathrm{TPTD}}$ was observed after weaning from CPB (T3) with a mean bias of $0.0078 \mathrm{~L} /$ minute $/ \mathrm{m}^{2}$ (LOA: -1.69 to $+1.68 \mathrm{~L} /$ minute $/ \mathrm{m}^{2}$ ) and an overall $\mathrm{PE}$ of $51 \%$. After 45 minutes (T4), pulse power calibration

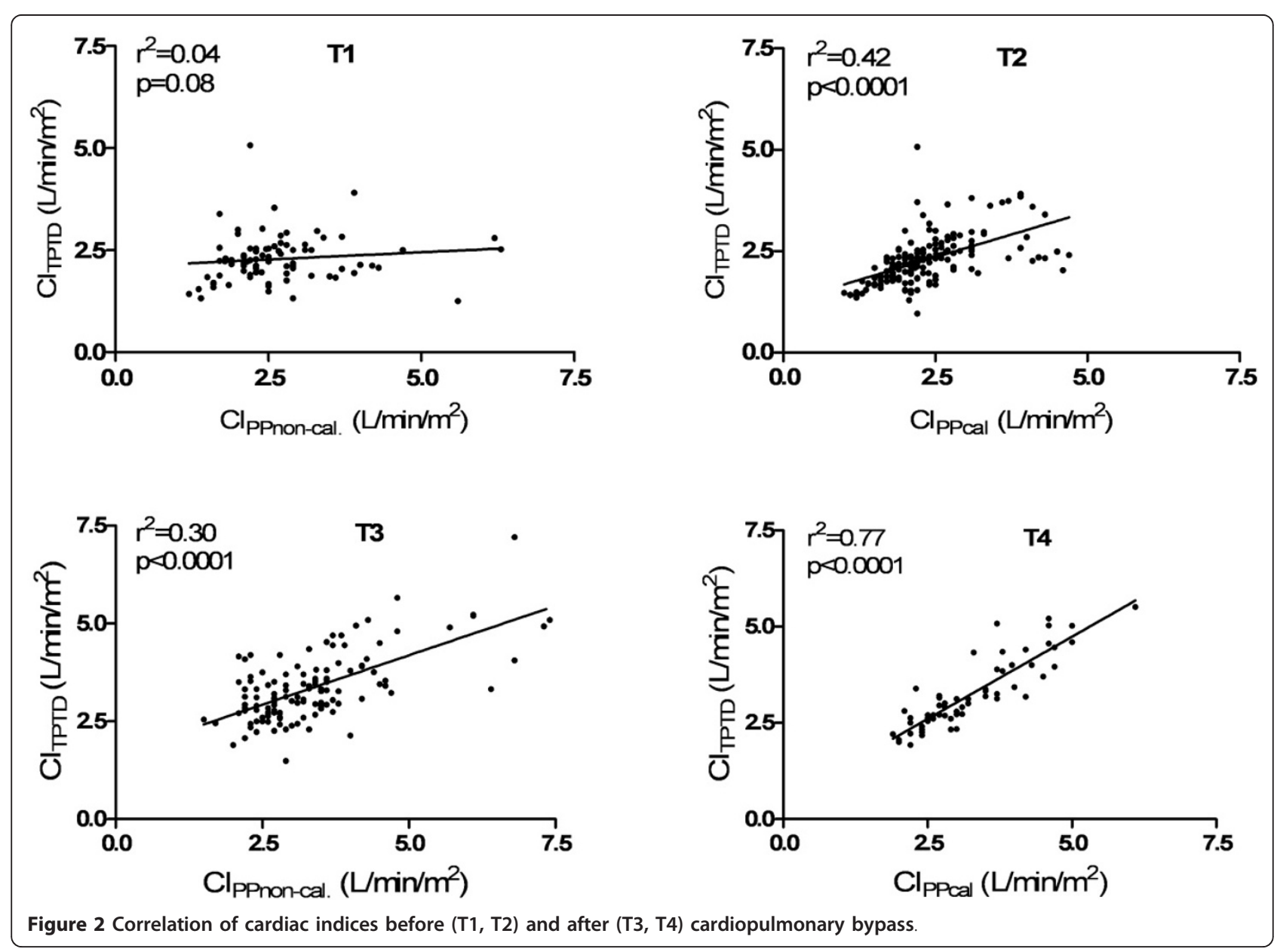


Table 2 Bland-Altman analysis showing $95 \%$ limits of agreement, confidence interval and percentage error

\begin{tabular}{|c|c|c|c|c|}
\hline & T1 & T2 & T3 & T4 \\
\hline $\mathrm{n}_{\text {data }} / \mathrm{n}_{\text {patient }}$ & $n=84 / n=42$ & $n=164 / n=42$ & $n=123 / n=42$ & $n=59 / n=40$ \\
\hline & Clppnon-cal. & Clppcal. & Clppnon-cal. & Clppcal. \\
\hline Mean (L/minute/m²) & 2.47 & 2.33 & 3.35 & 3.24 \\
\hline Bias $\left(\mathrm{L} / \mathrm{minute} / \mathrm{m}^{2}\right)$ & 0.36 & 0.075 & 0.0078 & 0.0071 \\
\hline SD of bias $\left(\mathrm{L} / \mathrm{minute} / \mathrm{m}^{2}\right)$ & 1.07 & 0.65 & 0.86 & 0.46 \\
\hline $\mathrm{Cl}$ of LOA (L/minute/m²) & 0.56 & 0.34 & 0.45 & 0.24 \\
\hline $95 \%$ Limits of agreement (L/minute $\left./ \mathrm{m}^{2}\right)$ & -1.73 to +2.46 & -1.19 to +1.34 & -1.69 to +1.68 & -0.89 to +0.91 \\
\hline Percentage error (\%) & 86 & 55 & 51 & 28 \\
\hline
\end{tabular}

$\mathrm{Cl}_{\text {PPnon-cal, }}$ cardiac index by uncalibrated pulse power analysis; $\mathrm{Cl}_{\text {PPcal, }}$ cardiac index by calibrated pulse power analysis; $\mathrm{Cl}_{\mathrm{TPTD}}$, cardiac index by transpulmonary thermodilution, $\mathrm{Cl}$ of LOA, confidence interval of the limits of agreement; Values are given as mean \pm SD.

was performed and $\mathrm{CI}_{\mathrm{PPcal}}$ showed a significant correlation to $\mathrm{CI}_{\mathrm{TPTD}}\left(\mathrm{r}^{2}=0.77, P<0.0001, \mathrm{n}=59\right)$ with a mean bias of $0.0071 \mathrm{~L} / \mathrm{minute} / \mathrm{m}^{2}$, LOA from -0.89 to $+0.91 \mathrm{~L} / \mathrm{minute} / \mathrm{m}^{2}$ and an overall PE of $28 \%$.

Trends of percentage changes in CI measured by pulse power analysis $\left(\Delta \mathrm{CI}_{\mathrm{PPnon} \text {-cal., }}, \Delta \mathrm{CI}_{\mathrm{PPcal}}\right)$ and transpulmonary thermodilution $\left(\Delta \mathrm{CI}_{\mathrm{TPTD}}\right)$ are presented in detail (see Additional file 1, Figure S1). Bland-Altman analysis showed a significant correlation for $\Delta \mathrm{CI}_{\mathrm{PPnon}-\mathrm{cal}}$ and $\Delta \mathrm{CI}_{\mathrm{TPTD}}\left(\mathrm{r}^{2}=\right.$ $0.27, P=0.003)$ in T1 with LOA from -62 to $67 \%$. After calibration (T2), correlation between $\triangle C \mathrm{I}_{\mathrm{PPcal}}$. and $\triangle \mathrm{CI}_{\text {TPTD }}$ again was statistically significant $\left(\mathrm{r}^{2}=0.30\right.$, $P<0.0001$ ), with LOA ranging from -42 to $36 \%$. In time period 3 after weaning from $\mathrm{CPB}, \triangle \mathrm{CI}_{\mathrm{PPnon} \text {-cal. }}$ correlated with $\Delta \mathrm{CI}_{\mathrm{TPTD}}\left(\mathrm{r}^{2}=0.18, P=0.01\right.$, LOA of -56 to $\left.56 \%\right)$. After calibration (T4), $\Delta \mathrm{CI}_{\mathrm{PPcal}}$ indicated a statistically significant association $\left(\mathrm{r}^{2}=0.52, P=0.005\right)$ with $\Delta \mathrm{CI}_{\mathrm{TPTD}}$ and showed LOA from -20 to $19 \%$. Results from ROC analysis showing the ability of $\Delta \mathrm{CI}_{\mathrm{PPnon} \text {-cal. }}$ and $\Delta \mathrm{CI}_{\mathrm{PPcal}}$. to predict a $\Delta \mathrm{CI}_{\mathrm{TPTD}}>15 \%$ are available (see Additional file 1 , Table S1). Only $\Delta \mathrm{CI}_{\mathrm{PP} \text { cal. }}$ was able to predict $\Delta \mathrm{CI}_{\mathrm{TPTD}}$ $>15 \%$ with a sensitivity of $90 \%$ and a specificity of $80 \%$ (AUC: $0.83, P=0.03$ ).

Correlation between MAP, $\mathrm{CI}_{\mathrm{PPnon-cal}}$ and $\mathrm{CI}_{\mathrm{PPcal} \text {., }}$ before and after $\mathrm{CPB}$ is illustrated in Figure 3. Before CPB (T1), higher MAP values were significantly associated with higher $\mathrm{CI}_{\text {PPnon-cal. }}\left(\mathrm{r}^{2}=0.26, P<0.0001\right)$. $\mathrm{CI}_{\mathrm{TPTD}}$ showed no correlation with MAP before $\left(\mathrm{r}^{2}<0.01, P=0.46\right)$ and after $\left(\mathrm{r}^{2}=0.03, P=0.05\right) \mathrm{CPB}$. There was no significant relationship between $\mathrm{CI}_{\mathrm{PPnon} \text {-cal. }}$ and systemic vascular resistance $\left(\mathrm{T} 1: \mathrm{r}^{2}=0.004, P=0.49 ; \mathrm{T} 2: \mathrm{r}^{2}=0.02, P=0.11\right.$; T3 $\mathrm{r}^{2}=0.02, P=0.10$, T4 $\left.\mathrm{r}^{2}=0.01, P=0.37\right)$ during the whole study period (T1 to T4).

\section{Discussion}

The main findings of the present investigation is that CI measurement by uncalibrated arterial pulse power analysis was not able to reliably measure CI compared with TPTD before and after CPB. After calibrating the pulse power algorithm with TPTD, PE was acceptable $(<30 \%)$ after $\mathrm{CPB}$. In a subset of the observed patients before
$\mathrm{CPB}$, higher MAP values showed a significant relationship with $\mathrm{CI}_{\mathrm{PPnon} \text {-cal. }}$.

Arterial pulse power analysis for continuous CI measurement was introduced several years ago. Until recently, this system required a lithium indicator dilution in order to calibrate for individual aortic compliance. The new monitoring system $\mathrm{LiDCO}_{\text {Rapid }}$ has been developed to provide continuous CI measurement without the need for calibration by using patient specific data for estimation of arterial compliance. To the best of our knowledge this is the first study analysing the accuracy of uncalibrated and calibrated pulse power analysis in patients undergoing coronary artery surgery.

Applying criteria proposed by Critchley and colleagues [21] to compare a new method of CI measurement with an established one, we regarded the pulse power analysis method as not interchangeable with the reference method (TPTD) if the percentage error exceeded $30 \%$. During the first 30 minutes after induction of anaesthesia we found no correlation between $\mathrm{CI}_{\text {PPnon-cal. and }}$ $\mathrm{CI}_{\text {TPTD }}$ and obtained a percentage error of $86 \%$. This value is considerably above the $30 \%$ limit of interchangeability and illustrates the difference we observed during the first period of time. To determine the influence of calibration, pulse power analysis was calibrated at defined time points before and after cardiopulmonary bypass by transpulmonary thermodilution. Accordingly, calibration should lead to an adequate accuracy and precision with respect to the reference technique, at least in the immediate period following calibration. In this context, we did not record continous cardiac output generated by the PiCCO monitoring system (PCCO), because due to our repeated calibrations we would have obtained a perfect PCCO (calibrated to the actual aortic impedance every 15 minutes by transpulmonary thermodilution), which would have induced a large bias in favor of PCCO. Several studies could demonstrate a less reliable measurement of $\mathrm{CO}$ by $\mathrm{PCCO}$ in patients undergoing cardiac surgery and in the presence of low vascular resistance after a longer period of time had elapsed after the last calibration $[10,22,23]$. 


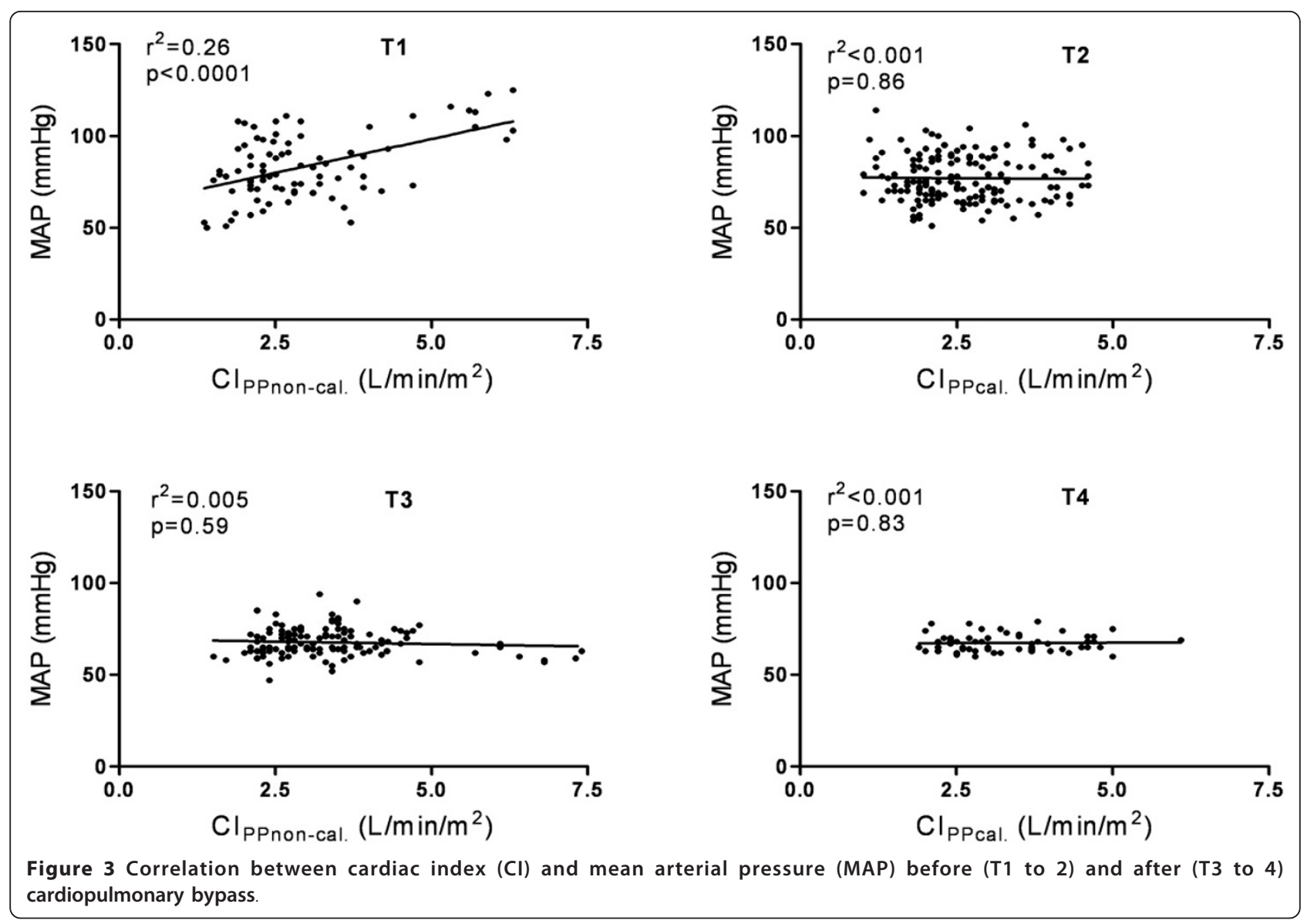

However, though we found a significant correlation between $\mathrm{CI}_{\mathrm{PPcal}}$ and $\mathrm{CI}_{\mathrm{TPTD}}\left(\mathrm{r}^{2}=0.42, P<0.0001\right)$ at $\mathrm{T} 2$ after pulse power calibration before CPB, PE was $55 \%$, clearly exceeding the $30 \%$ limit mentioned before. After cardiopulmonary bypass, $\mathrm{CI}_{\mathrm{PP} \text { non-cal. }}$ and $\mathrm{CI}_{\mathrm{PP} \text { cal. }}$. once again showed a significant correlation with $\mathrm{CI}_{\mathrm{TPTD}}$ and $\mathrm{PE}$ was $51 \%$ and $28 \%$. As recommended by recent literature, we calculated the precision of $\mathrm{CI}_{\mathrm{PPnon} \text {-cal./cal. before and }}$ after CPB [24] and obtained a sufficient precision confirming our personal experience as we observed no rapid changes in CI during data recording. An explanation of these results can be found in the method underlying uncalibrated arterial pulse wave analysis. The physiological foundation of arterial pressure curves is the proportional relation of aortic pulse pressure and stroke volume and their inverse relation to aortic compliance $[25,26]$. Based on the windkessel model by Otto Frank arterial waveform analysis is influenced by three vascular properties: resistance, compliance and impedance [27]. However, several confounders such as individual changes in vascular compliance and resistance [28], gender [29] or vascular diseases [30] may influence this relationship in an unforeseen way. Recently, detrimental influence of significant changes of blood pressure on the accuracy of uncalibrated waveform analysis was reported both in animals and humans $[25,31]$. Because of the individually different relationship between changes in aortic compliance and changes in stroke volume, the increased arterial waveform could be inadvertently misinterpreted as an increase in stroke volume [32]. In accordance, we could demonstrate a significant correlation between MAP and $\mathrm{CI}_{\text {PPnon-cal. }}\left(\mathrm{r}^{2}\right.$ $=0.26, P<0.0001)$ at $\mathrm{T} 1$, meaning that higher MAP values

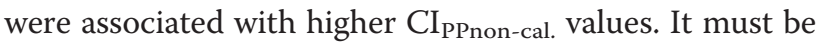
noted, however, that this correlation is based on few data points from a small number of patients observed in T1. Additionally, the absence of correlation between MAP and $\mathrm{CI}_{\mathrm{TPTD}}$ emphasizes the fact that arterial compliance differed from patient to patient. As mentioned above, aortic compliance is linked to a non-linear response to arterial pressure and since the individual aortic cross sectional area is unknown, these uncertainties could lead to imprecision in determination of cardiac index by arterial waveform analysis. Therefore, this emphasizes the use of thermodilution to provide maximum accuracy during haemodynamic measurements.

Changes of systemic vascular resistance during surgery or intensive care therapy are caused by various factors such as temperature, fluid administration or decreased 
and increased sympathetic tone. We observed a significant lower systemic vascular resistance index $(P<0.05)$ after weaning from $\mathrm{CPB}$ but found no correlation between $\mathrm{CI}_{\text {TPTD }}, \mathrm{CI}_{\text {PPnon-cal./cal. and systemic vascular }}$ resistance before and after $\mathrm{CPB}$. In contrast to our findings, other observations recently reported a significant negative impact on the accuracy of arterial pulse wave analysis in patients with septic shock $[33,34]$ and due to changes in vascular tone by vasoactive agents or intraperitoneal hypertension $[19,35]$. To avoid misinterpretation in the presence of disturbing factors and to achieve the required precision, monitoring systems based on arterial waveform analysis should be able to recalculate arterial compliance at short intervals [32]. In this context, the frequency of recalculation and the underlying algorithm of uncalibrated pulse power analysis have not yet been published.

Besides the acquisition of exact CI data, the $\mathrm{LiDCO}_{R a-}$ pid monitoring system was also developed for evaluation and reflection of haemodynamic changes and trends during the perioperative period. In case of a critically ill patient, physicians are advised by the manufacturer to calibrate the system. Many patients undergoing elective major surgical procedures exhibit several co-morbidities, such as coronary artery disease and organ dysfunction without being in a life-threatening condition. Accordingly, with respect to this patient population most clinicians are more interested in perioperative haemodynamic changes or trends than intermittent absolute CI values. Furthermore, to avoid misleading interpretation of the Bland-Altman analysis, trends of percentage changes in CI were calculated [36] and changes of CI obtained by transpulmonary thermodilution $<15 \%$ were excluded from further analysis as noise [20].

In our study, trends of percentage changes in $\mathrm{CI}$ measured by pulse power analysis $\left(\Delta \mathrm{CI}_{\mathrm{PPnon} \text {-cal./PPcal. }}\right)$ and transpulmonary thermodilution $\left(\Delta \mathrm{CI}_{\mathrm{TPTD}}\right)$ revealed a weak but significant correlation before and after CPB. Calibration of pulse power analysis improved statistical significance, as well as the measurements obtained at lower MAP values immediately after CPB. We observed the best correlation of changes in CI between transpulmonary thermodilution and pulse power analysis after $\mathrm{CPB}$ and calibration; however, the patient sample was limited at $\mathrm{T} 4$ and, therefore, these data should be interpreted with caution. However, ROC analysis for prediction of $\Delta \mathrm{CI}_{\mathrm{TPTD}}>15 \%$ showed that only $\Delta \mathrm{CI}_{\mathrm{PPcal}}$. was able to track haemodynamic changes and trends with sufficient sensitivity and specificity.

Some limitations of our study must be noted. We investigated a monitoring system developed to reflect haemodynamic trends, rather than measuring accurate CI. However, a prerequisite for using a system to guide goal-directed haemodynamic therapy in clinical settings is to understand the precision and the limitation of a monitoring technique. Furthermore, transpulmonary thermodilution implies some limitations particularly after weaning from cardiopulmonary bypass with ongoing thermal changes, leading to a higher bias caused by reduced accuracy of the reference technique [10]. However, we observed better correlation between $\mathrm{CI}$ and trends of $\mathrm{CI}$ by transpulmonary thermodilution and calibrated pulse power analysis after weaning from $\mathrm{CPB}$. Due to the fact that we did not assess CI by uncalibrated and calibrated pulse power analysis at the same time but under different haemodynamic conditions, this could have induced a small bias especially in the immediate period following CPB. In this context, $\mathrm{CI}_{\mathrm{PP}}$ is probably also influenced by systolic arterial pressure which was unfortunately not recorded during the study period. Finally, we excluded patients with haemodynamic instability or shock and investigated patients undergoing elective coronary surgery with normal left ventricular function and without continuous application of vasoactive drugs. Therefore, our results cannot be extrapolated to patients with impaired left ventricular function, low cardiac output or patients receiving inotropic or vasoactive support.

\section{Conclusions}

With respect to the absolute values of CI measurement, the less invasive technique of uncalibrated pulse power analysis was not interchangeable with transpulmonary thermodilution, both before and after CPB. Calibration of pulse power analysis improved accuracy, but PE was only acceptable after CPB. Correlation between MAP and $\mathrm{CI}_{\mathrm{PPnon} \text {-cal. }}$ in a subset of patients at $\mathrm{T} 1$ suggests that in the presence of high blood pressure, data from uncalibrated pulse power analysis should probably be interpreted with caution. Only calibrated pulse power analysis was able to reliably track haemodynamic changes and trends. As only a homogeneous elective patient collective was investigated, the present results, however, cannot be generalized and transferred to other groups of patients.

\section{Key messages}

- Uncalibrated pulse power analysis was not interchangeable with transpulmonary thermodilution before and after CPB.

- Calibration improved accuracy, but pulse power analysis was still not consistently interchangeable with transpulmonary thermodilution.

- Only calibrated pulse power analysis was able to track the percentage of changes in CI measured by transpulmonary thermodilution.

- Uncalibrated pulse power analysis was significantly influenced by MAP in a subset of the observed 
patients, requiring further investigation in different patient populations.

\section{Additional material}

Additional file 1: Figure S1 and Table S1. Figure S1: Correlation of changes in cardiac index $(\Delta \mathrm{Cl})$. Correlation and Bland-Altman analysis of changes (\%) in cardiac index $(\Delta \mathrm{Cl})$ measured by pulse power analysis $\left(\Delta C_{P P}\right)$ and transpulmonary thermodilution $\left(\Delta \mathrm{Cl}_{\mathrm{TPTD}}\right)$ before ( $\mathrm{T} 1$ to 2 ) and after (T3 to 4) cardiopulmonary bypass. Table S1: ROC-analysis to predict a change in Cl by TPTD $\left(\Delta \mathrm{Cl}_{\text {TPTD }}\right)>15 \%$. Area under the Receiver Operating Characteristic Curve showing the ability of uncalibrated and calibrated pulse power analysis to predict a change in CI by TPTD $\left(\Delta \mathrm{C}_{\text {TPTD }}\right)>15 \%$.

\section{Abbreviations}

CABG: coronary artery bypass grafting; Cal: calibrated; Cl: cardiac index; CPB: cardiopulmonary bypass; ECG: electrocardiogram; HR: heart rate; LOA: limits of agreement; MAP: mean arterial pressure; NIBP: non-invasive blood pressure; Non-cal: uncalibrated; PAC: pulmonary artery catheter; PE: percentage error; PP: pulse power analysis; $\mathrm{SpO}_{2}$ : peripheral oxygen saturation; TPTD: transpulmonary thermodilution.

\section{Acknowledgements}

The authors are indebted to Volkmar Hensel-Bringmann for excellent technical assistance and logistic support, and to Juergen Hedderich PhD for statistical advice.

We are greatly indebted to Dr. Amke Caliebe for the excellent statistical advice and revision of this manuscript.

\section{Author details}

${ }^{1}$ Department of Anaesthesiology and Intensive Care Medicine, University Hospital Schleswig-Holstein, Campus Kiel, Schwanenweg 21, 24105 Kiel, Germany. ${ }^{2}$ Department of Cardiothoracic and Vascular Surgery, University Hospital Schleswig-Holstein, Campus Kiel, Arnold-Heller-Straße 7, 24105 Kiel, Germany.

\section{Authors' contributions}

$\mathrm{OB}$ conducted the study, analyzed the data and drafted the manuscript. JR has made substantial contributions to data acquisition and has been involved in drafting the manuscript. JH helped to draft the manuscript and analyse the data. MG participated in statistical analysis and helped draft the manuscript. PM participated in study design and coordination and helped to draft the manuscript. JS participated in data analysis and coordination of the study. MS has been involved in drafting the manuscript and participated in study design. BB has been involved in drafting the manuscript, data analysis and has given final approval of the version to be published. All authors read and approved the final manuscript.

\section{Competing interests}

Prof. Bein is a member of the medical advisory board of Pulsion Medical Systems (Munich, Germany) and has received honoraria for consulting and giving lectures. All other authors declare that they have no competing interests.

Received: 27 October 2010 Revised: 7 December 2010 Accepted: 28 February 2011 Published: 28 February 2011

\section{References}

1. Grocott MP, Mythen MG, Gan TJ: Perioperative fluid management and clinical outcomes in adults. Anesth Analg 2005, 100:1093-1106.

2. Jans O, Tollund C, Bundgaard-Nielsen M, Selmer C, Warberg J, Secher NH: Goal-directed fluid therapy: stroke volume optimisation and cardiac dimensions in supine healthy humans. Acta Anaesthesiol Scand 2008, 52:536-540.

3. Pearse R, Dawson D, Fawcett J, Rhodes A, Grounds RM, Bennett ED: Early goal-directed therapy after major surgery reduces complications and duration of hospital stay. A randomised, controlled trial (ISRCTN38797445). Crit Care 2005, 9:R687-693.

4. Rivers E, Nguyen B, Havstad S, Ressler J, Muzzin A, Knoblich B, Peterson E, Tomlanovich M: Early goal-directed therapy in the treatment of severe sepsis and septic shock. N Engl J Med 2001, 345:1368-1377.

5. Breukers RM, Sepehrkhouy S, Spiegelenberg SR, Groeneveld AB: Cardiac output measured by a new arterial pressure waveform analysis method without calibration compared with thermodilution after cardiac surgery. J Cardiothorac Vasc Anesth 2007, 21:632-635.

6. Friesecke S, Heinrich A, Abel P, Felix SB: Comparison of pulmonary artery and aortic transpulmonary thermodilution for monitoring of cardiac output in patients with severe heart failure: validation of a novel method. Crit Care Med 2009, 37:119-123.

7. Reinke RT, Higgins CB: Pulmonary infarction complicating the use of Swan-Ganz catheters. Br J Radiol 1975, 48:885-888.

8. Connors AF Jr, Speroff T, Dawson NV, Thomas C, Harrell FE Jr, Wagner D, Desbiens N, Goldman L, Wu AW, Califf RM, Fulkerson WJ Jr, Vidaillet H, Broste S, Bellamy P, Lynn J, Knaus WA: The effectiveness of right heart catheterization in the initial care of critically ill patients. SUPPORT Investigators. JAMA 1996, 276:889-897.

9. Richard C, Warszawski J, Anguel N, Deye N, Combes A, Barnoud D, Boulain T, Lefort Y, Fartoukh M, Baud F, Boyer A, Brochard L, Teboul JL: Early use of the pulmonary artery catheter and outcomes in patients with shock and acute respiratory distress syndrome: a randomized controlled trial. JAMA 2003, 290:2713-2720.

10. Sander M, von Heymann C, Foer A, von Dossow V, Grosse J, Dushe S, Konertz WF, Spies CD: Pulse contour analysis after normothermic cardiopulmonary bypass in cardiac surgery patients. Crit Care 2005, 9: R729-734.

11. Ritter S, Rudiger A, Maggiorini M: Transpulmonary thermodilution-derived cardiac function index identifies cardiac dysfunction in acute heart failure and septic patients: an observational study. Crit Care 2009, 13:R133.

12. Hillis $L D$, Firth $B G$, Winniford MD: Comparison of thermodilution and indocyanine green dye in low cardiac output or left-sided regurgitation. Am J Cardiol 1986, 57:1201-1202.

13. Sakka SG, Reinhart $K$, Meier-Hellmann A: Comparison of pulmonary artery and arterial thermodilution cardiac output in critically ill patients. Intensive Care Med 1999, 25:843-846.

14. Breukers RM, Groeneveld AB, de Wilde RB, Jansen JR: Transpulmonary versus continuous thermodilution cardiac output after valvular and coronary artery surgery. Interact Cardiovasc Thorac Surg 2009, 9:4-8.

15. Sander M, Spies CD, Grubitzsch H, Foer A, Muller M, von Heymann C: Comparison of uncalibrated arterial waveform analysis in cardiac surgery patients with thermodilution cardiac output measurements. Crit Care 2006, 10:R164

16. Hamilton TT, Huber LM, Jessen ME: PulseCO: a less-invasive method to monitor cardiac output from arterial pressure after cardiac surgery. Ann Thorac Surg 2002, 74:S1408-1412.

17. Belloni L, Pisano A, Natale A, Piccirillo MR, Piazza L, Ismeno G, De Martino G: Assessment of fluid-responsiveness parameters for off-pump coronary artery bypass surgery: a comparison among LiDCO, transesophageal echochardiography, and pulmonary artery catheter. I Cardiothorac Vasc Anesth 2008, 22:243-248.

18. Bein B, Meybohm P, Cavus E, Renner J, Tonner PH, Steinfath M, Scholz J, Doerges $\mathrm{V}$ : The reliability of pulse contour-derived cardiac output during hemorrhage and after vasopressor administration. Anesth Analg 2007, 105:107-113.

19. Yamashita K, Nishiyama T, Yokoyama T, Abe H, Manabe M: Effects of vasodilation on cardiac output measured by PulseCO. J Clin Monit Comput 2007, 21:335-339.

20. Critchley LA, Lee A, Ho AM: A critical review of the ability of continuous cardiac output monitors to measure trends in cardiac output. Anesth Analg 2010, 111:1180-1192.

21. Critchley LA, Critchley JA: A meta-analysis of studies using bias and precision statistics to compare cardiac output measurement techniques. J Clin Monit Comput 1999, 15:85-91.

22. Halvorsen PS, Espinoza A, Lundblad R, Cvancarova M, Hol PK, Fosse E, Tonnessen TI: Agreement between PiCCO pulse-contour analysis, pulmonal artery thermodilution and transthoracic thermodilution during off-pump coronary artery by-pass surgery. Acta Anaesthesiol Scand 2006, 50:1050-1057. 
23. Yamashita K, Nishiyama T, Yokoyama T, Abe H, Manabe M: The effects of vasodilation on cardiac output measured by PiCCO. I Cardiothorac Vasc Anesth 2008, 22:688-692.

24. Squara P, Cecconi M, Rhodes A, Singer M, Chiche JD: Tracking changes in cardiac output: methodological considerations for the validation of monitoring devices. Intensive Care Med 2009, 35:1801-1808.

25. Cooper ES, Muir WW: Continuous cardiac output monitoring via arterial pressure waveform analysis following severe hemorrhagic shock in dogs. Crit Care Med 2007, 35:1724-1729.

26. Boulain T, Achard JM, Teboul JL, Richard C, Perrotin D, Ginies G: Changes in $\mathrm{BP}$ induced by passive leg raising predict response to fluid loading in critically ill patients. Chest 2002, 121:1245-1252.

27. Sagawa K, Lie RK, Schaefer J: Translation of Otto Frank's paper "Die Grundform des Arteriellen Pulses" Zeitschrift fur Biologie 37: 483-526 (1899). J Mol Cell Cardiol 1990, 22:253-277.

28. Mayer J, Boldt J, Schollhorn T, Rohm KD, Mengistu AM, Suttner S: Semiinvasive monitoring of cardiac output by a new device using arterial pressure waveform analysis: a comparison with intermittent pulmonary artery thermodilution in patients undergoing cardiac surgery. $\mathrm{Br} J$ Anaesth 2007, 98:176-182.

29. Winer N, Sowers JR, Weber MA: Gender differences in vascular compliance in young, healthy subjects assessed by pulse contour analysis. J Clin Hypertens (Greenwich) 2001, 3:145-152.

30. Covic A, Haydar AA, Bhamra-Ariza P, Gusbeth-Tatomir P, Goldsmith DJ: Aortic pulse wave velocity and arterial wave reflections predict the extent and severity of coronary artery disease in chronic kidney disease patients. J Nephrol 2005, 18:388-396.

31. Eleftheriadis S, Galatoudis Z, Didilis V, Bougioukas I, Schon J, Heinze H, Berger KU, Heringlake M: Variations in arterial blood pressure are associated with parallel changes in FlowTrac/Vigileo-derived cardiac output measurements: a prospective comparison study. Crit Care 2009, 13:R179.

32. Manecke GR Jr: Cardiac output from the arterial catheter: deceptively simple. J Cardiothorac Vasc Anesth 2007, 21:629-631.

33. Sakka SG, Kozieras J, Thuemer O, van Hout N: Measurement of cardiac output: a comparison between transpulmonary thermodilution and uncalibrated pulse contour analysis. Br J Anaesth 2007, 99:337-342.

34. Monnet X, Anguel N, Naudin B, Jabot J, Richard C, Teboul JL: Arterial pressure-based cardiac output in septic patients: different accuracy of pulse contour and uncalibrated pressure waveform devices. Crit Care 2010, 14:R109

35. Gruenewald M, Renner J, Meybohm P, Hocker J, Scholz J, Bein B: Reliability of continuous cardiac output measurement during intra-abdominal hypertension relies on repeated calibrations: an experimental animal study. Crit Care 2008, 12:R132.

36. Linton NW, Linton RA: Is comparison of changes in cardiac output, assessed by different methods, better than only comparing cardiac output to the reference method? Br J Anaesth 2002, 89:336-337, author reply $337-339$.

doi:10.1186/cc10065

Cite this article as: Broch et al:: Uncalibrated pulse power analysis fails to reliably measure cardiac output in patients undergoing coronary artery bypass surgery. Critical Care 2011 15:R76.

\section{Submit your next manuscript to BioMed Central and take full advantage of:}

- Convenient online submission

- Thorough peer review

- No space constraints or color figure charges

- Immediate publication on acceptance

- Inclusion in PubMed, CAS, Scopus and Google Scholar

- Research which is freely available for redistribution

Submit your manuscript at www.biomedcentral.com/submit
Biomed Central 